\title{
O USO DA MODELAGEM COMPUTACIONAL EM FUNÇÕES DE CINEMÁTICA COM O MODELLUS
}

\section{ARTIGO ORIGINAL}

CARDOSO, Kaio Felipe Nink ${ }^{1}$

JUNIOR, Gilberto Nunes da Silva ${ }^{2}$

JÚNIOR, João Hermano Torreiro de Carvalho ${ }^{3}$

CARDOSO, Kaio Felipe Nink. JUNIOR, Gilberto Nunes da Silva. JÚNIOR, João Hermano Torreiro de Carvalho. $\mathbf{O}$ uso da modelagem computacional em funções de cinemática com o Modellus. Revista Científica Multidisciplinar Núcleo do Conhecimento. Ano 05, Ed. 03, Vol. 04, pp. 117-140. Março de 2020. ISSN: 24480959, Link de acesso: https://www.nucleodoconhecimento.com.br/educacao/cinematica-com-0modellus

\section{RESUMO}

A aplicação da Física ainda se mostra um desafio para os meios de ensino, baseandose nos métodos tradicionais, podendo excluir outros meios mais modernos e que façam um uso maior de tecnologias educacionais. Fizemos uso do programa de modelagem computacional, Modellus, voltado principalmente para aplicações de Cinemática, com dois exercícios envolvendo os movimentos de Lançamento Vertical e Lançamento Oblíquo, uma vez que são levantadas dificuldades quanto à compreensão, possivelmente, gerada pelos métodos educacionais expositivos. Aplicamos os exercícios em um questionário com 15 alunos da $2^{\underline{a}}$ Série do Ensino

\footnotetext{
${ }^{1}$ Graduando em Ciência da Computação, Técnico em Informática.

2 Técnico em Informática.

${ }^{3}$ Mestre em educação.
} 
Médio do IFBA/ Barreiras, como amostra para análise da forma que os estudantes avaliam o atual ensino da Física e as possíveis necessidades de novas metodologias na educação dessa Ciência.

Palavras chaves: Ensino de Física, software, modelagem computacional, avaliação estudantil.

\section{INTRODUÇÃO}

Em meio a inúmeros avanços tecnológicos, muito se tem a discutir sobre como a educação está sendo aplicada, visto que o giz e quadro negro ainda são fortemente utilizados em sala de aula, podendo não dar espaço para atividades mais dinâmicas. No que tange ao aspecto qualitativo, temos uma escola do século XVIII em pleno século XXI (VALENTE apud LOPES; FEITOSA, 2009). Isto se torna perceptível ao reparar em como o modelo de educação não apresentou diversas transformações quanto à sua forma de aplicação.

Percebe-se que os alunos demonstram uma certa dificuldade na aprendizagem das Ciências Exatas, como a Física, por exemplo. A utilização de métodos tradicionais de ensino e ausência de meios pedagógicos modernos constituem-se razões deste problema (SANTOS; ALVES; MORET, 2006). Em contrapartida, sabe-se que muitos ambientes de ensino podem não dispor de recursos suficientes para aprimorar o ensino em sala de aula, bem como a capacitação profissional adequada.

Apresentando-se como um software gratuito, o Modellus é uma aplicação voltada para a modelagem computacional de funções aplicadas para o ensino de cinemática tanto em Ciências Matemáticas quanto em Ciências Físicas, permitindo ao usuário fazer e refazer representações, explorando-as sobre as mais diversas perspectivas (VEIT; TEODORO, 2002). Outra característica importante provida pelo Modellus é a representação múltipla, i.e., o usuário pode criar, ver e interagir com as representações analíticas, analógicas e gráficas dos objetos matemáticos (TEODORO apud ARAUJO, 2002). 
Dentre os assuntos trabalhados nos ambientes educacionais em Física acerca de mecânica, podemos adentrar ao estudo de cinemática, tendo um foco para os movimentos de Lançamento Vertical e Lançamentos Oblíquos. Torna-se possível assim aplicá-los com auxílio do Modellus através de exercícios comuns dos temas, uma vez que por meios didáticos tradicionais podem não cativar o interesse do aluno, mas com um aprimoramento da técnica do software, segundo vários autores na área de ensino da Física, pode-se obter um outro resultado.

Visando uma boa aplicação dos exercícios, fora desenvolvido um questionário voltado para os alunos do ensino médio do Instituto Federal de Educação, Ciência e Tecnologia da Bahia - Campus Barreiras dos cursos de nível Técnico Integrado, para assim comparar o desempenho do ensino das Ciências Matemáticas e Físicas com e sem o uso do Modellus.

\section{USO DO MODELLUS NO ENSINO DE FÍSICA}

A Física, normalmente, representa uma ciência de estudo árduo, que a maioria das pessoas apresentam dificuldade em entendê-la e interpretá-la, sendo o estudo dos fenômenos físicos que ocorrem à nossa volta. A necessidade do ser humano de compreender o ambiente que o cerca e explicar os fenômenos naturais é a gênese da Física (RAMALHO JUNIOR; FERRARO; SOARES, 1998, p.2). Desta forma, percebese que a Física é de suma importância ao desenvolvimento humano, que de acordo o físico contemporâneo Michio Kaku, está em todo lugar, como: na evolução das tecnologias, dos meios de comunicação e transporte, entre outros.

Não se nega a relevância desse estudo e que deve ser ensinado como forma de observar o mundo e entendê-lo, entretanto, o ensino do mesmo, ainda é muito defasado atualmente. De acordo a pesquisa de Rosa, Perez e Drum (2009), os físicos entrevistados afirmaram que há a importância dos experimentos físicos, como forma de demonstração da realidade, à interpretação do discente, que seria a forma até então mais adequada de lecionar. A partir disso, percebemos que a educação em Física não é muito atraente, apresentando muitos cálculos e visualização lógica de sistemas, que compreendem a falta de interesse na mesma. 
Na maioria das vezes, a falta de técnicas metodológicas diferentes é responsável por um elevado número de "analfabetos" em Física no mundo. A pesquisa de Teixeira, Júnior e Golfette (2004), observada na figura 1, nos mostra boa parte da realidade desta educação no Brasil, lidando com estes problemas de ensino: falta de preparação dos alunos (requer-se um conhecimento prévio em matemática e uma boa interpretação aos sistemas), sistema educacional antigo, falta de materiais de ensino atraentes, infraestrutura e formação dos professores.

Figura 1 - Dificuldades no ensino de Física (TEIXEIRA; JÚNIOR; GOLFETTE, 2004)

\section{Quais os grandes desafios que o Brasil deve enfrentar para melhorar o ensino de Física? \\ (Principais respostas)}

Melhorar políticas em C \& T

Repensar os conteúdos

Melhorar a condiçẫo dos alunos

Melhorar as políticas em Educaçã̃o

Melhorar os materiais de apoio

Melhorar a infraestrutura da escola

Melhorar a formaçẫo dos professores

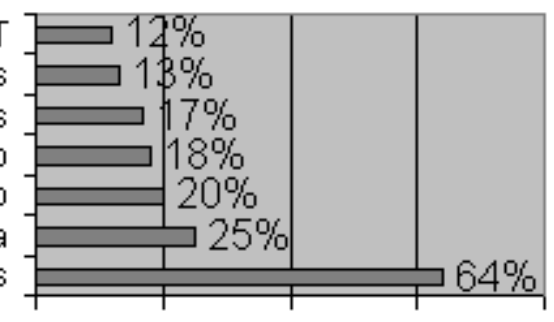

$0 \% \quad 20 \% \quad 40 \% \quad 60 \% \quad 80 \%$

"Nas narrativas dos professores destacam-se a visão que esses têm de física, pois para uns (os que compartilham da impossibilidade desse ensino), a física se reduz a cálculos, a situações-problema nas quais se exige um complexo raciocínio matemático e algébrico; tal situação, no entender deles, ainda está em processo de desenvolvimento no aluno das séries iniciais, não permitindo contemplá-lo nessa etapa escolar." (ROSA; PEREZ; DRUM, 2009, p. 362)

Conforme o gráfico da figura 1, a formação dos professores é uma questão a ser tratada, contudo, mesmo sendo apontada aproximadamente três vezes mais do que os materiais de apoio. Percebe-se que estes, se apropriado de táticas de ensino melhores, também ajudará a diminuir o índice da formação dos professores, já que 
atuará em todos os níveis educacionais. Formas alternativas seriam, a internet como suporte técnico e o aumento de procedimentos experimentais que induzem o aluno à visualização, porém, muitos sistemas estudados não são possíveis de reproduzi-los pelo fato de trabalharem com sistemas conservativos (no vácuo), portanto, uma possibilidade referente a esse questionamento, seria o uso de softwares de modelagem computacional, um exemplo é o Modellus.

Segundo Aliprandini (2009), formas alternativas de ensino de Física, através de simulações ou na modelagem do ambiente real possibilita a mudança de padrões de ensino tradicionais (ALIPRANDINI; SCHUHMACHER; SANTOS, 2009).

Modellus é um programa educacional de modelagem computacional que permite a criação, simulação de fenômenos físicos e matemáticos, usado no ensino de ciências exatas. Ele permite criar, preparar e resolver uma questão, usando da representação matemática do sistema para simulá-lo, assim manipulando as variáveis (tempo, distância, etc) e observando como ocorre o fenômeno físico. A ideia é a pessoa utilizálo como forma de interpretação dos problemas, observando o que cada grandeza exerce de influência, sem se importar com cálculos.

"O programa pode ser considerado como animação interativa, e considerado como ferramenta computacional que auxilia a construção do conhecimento, e ser usado para ressignificar o conhecimento mediante significados claros, estáveis e diferenciados previamente existentes na estrutura cognitiva do aluno." (ALIPRANDINI; SCHUHMACHER; SANTOS, 2009, p. 1374)

O que se pretende ao usar o software no ensino de Física, é que os aprendizes de Física saibam usar os conhecimentos científicos adquiridos na tomada de decisões, a partir do desenvolvimento de seu intelecto de dois modos, exploratório e expressivo, de acordo Aliprandini, Schuhmacher e Santos (2009). O modo exploratório diz respeito à localização de funções analíticas, analógicas e gráficas no programa, que desenvolve o saber matemático pela associação, além da exploração dos sistemas 
de outras pessoas; e o modo expressivo, como forma de demonstração da criatividade, criando modelos próprios dos usuários.

Para Veit e Teodoro (2002), o Modellus possibilita uma "aprendizagem construtivista", ocorrendo a partir da definição das ideias, tendo benefício em nível cognitivo. Este processo se dá pelo fato do uso do software não ser de todo trivial, sendo um processo lento de aprendizagem que necessita de um pensamento arquitetônico para construção das simulações, tendo a construção não só cognitiva, mas também pessoal, atingindo o objetivo do desenvolvimento da visão de mundo de alunos a partir do conhecimento científico adquirido.

Um aspecto que mostra a utilização do Modellus no âmbito educacional, é que ele é usado em instituições ao redor do mundo, como no projeto Institute of Physics do Reino Unido. O programa ganhou reconhecimento mundial em 1996 com o prêmio de "1996 Software Contest of the Journal Computer in Physics" e em 1998 com 1 lugar no Concurso Nacional de Software Microsoft, 1998 em Lisboa (VEIT e TEODORO, 2002). A figura 2 apresenta o software Modellus em forma de mapa conceitual. Sucintamente, a modelagem computacional, relacionada com a ciencia da natureza Física, faz a relação entre os as equações e funções da Física (algoritmo) que descrevem o fenômeno observado (teoria) e sua aplicação por meio da simulação computacional, dentro de uma linguagem comum ao usuário, ou seja, sem necessidade de aprender a programar em outra linguagem, senão aquela que já é vista em sala de aula (figura 3). 
Figura 2 - Usos para o software (VEIT; TEODORO, 2002)

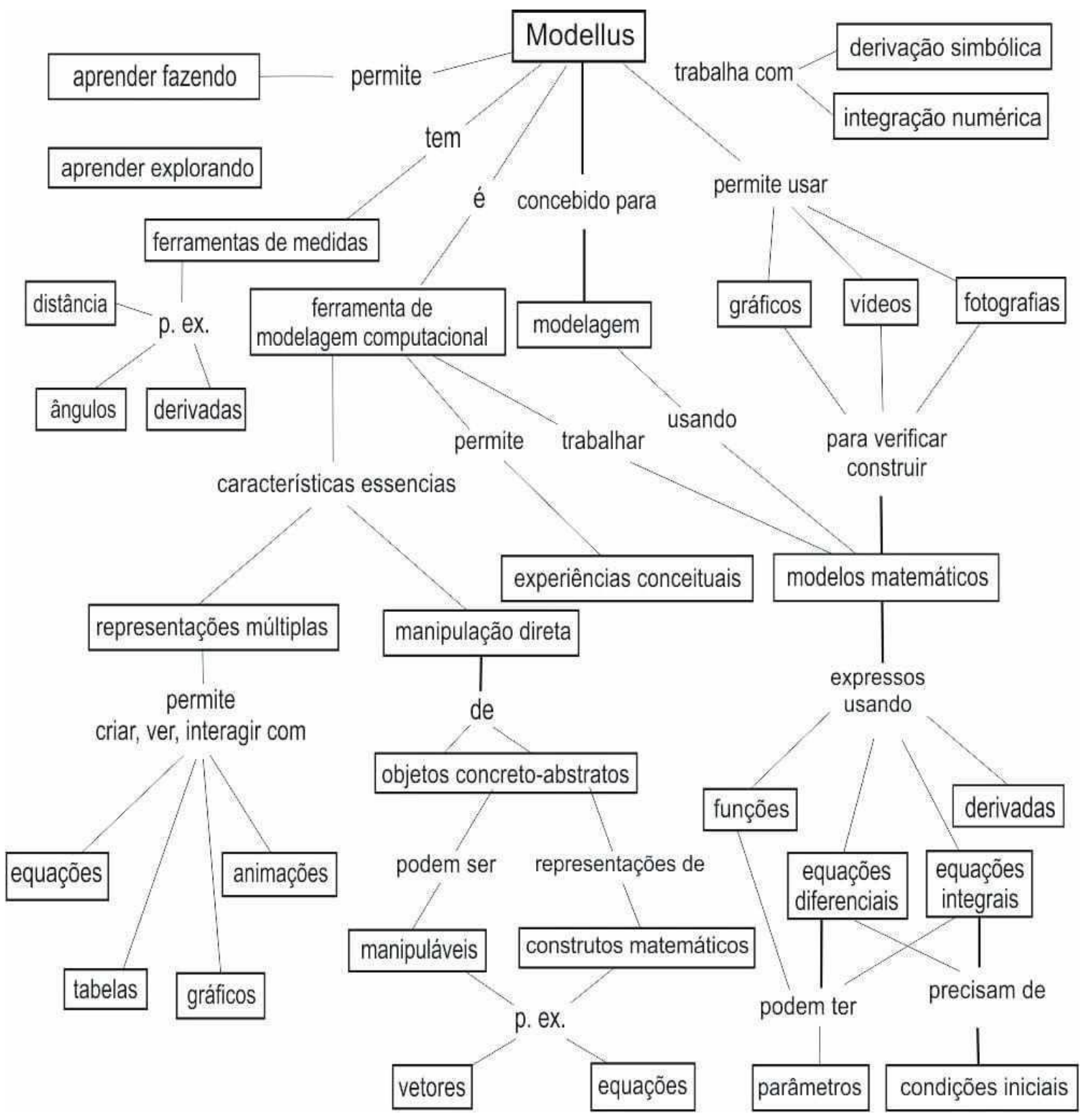


Figura 3 - Relação de conhecimentos na Modelagem Computacional (Autores, 2017)

\section{Arquitetura}

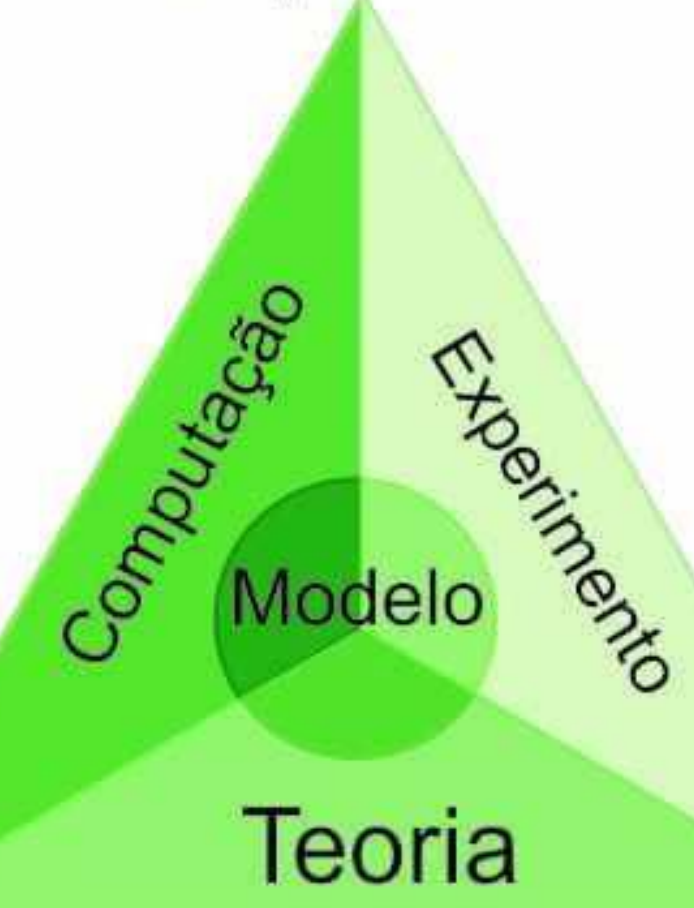

\section{Aplicação}

\section{Algoritmo}

\section{MATERIAL E MÉTODOS}

\subsection{EXERCÍCIOS COMO EXEMPLIFICAÇÃO UTILIZANDO O MODELLUS}

A cinemática é a parte da Mecânica que descreve os movimentos, procurando determinar a posição, a velocidade e a aceleração de um corpo em cada instante. (RAMALHO JUNIOR; FERRARO; SOARES, 1998). Nos ambientes educacionais, tem-se as aplicações, muitas vezes teóricas expositivas, dos temas previamente abordados. Foram trabalhados acerca disso com dois exercícios teóricos retirados de um livro didático do ensino médio:

Ex. 01. (Lançamento Vertical) Dois móveis A e B são lançados verticalmente para cima, com a mesma velocidade inicial de $15 \mathrm{~m} / \mathrm{s}^{2}$, do mesmo ponto. O móvel A é 
lançado no instante $\mathrm{t}=0 \mathrm{~s}$ e o móvel $\mathrm{B}$ é lançado $2 \mathrm{~s}$ depois. Determine, a contar do ponto de lançamento, a posição e o instante do encontro dos móveis. Adote $\mathrm{g}=10 \mathrm{~m} / \mathrm{s}^{2}$ e despreze a resistência do ar.

Ex. 02. (Lançamento Oblíquo) Um corpo é lançado obliquamente no vácuo com velocidade inicial $\mathrm{v} 0=100 \mathrm{~m} / \mathrm{s}$, numa direção que forma com a horizontal um ângulo $\theta$ tal que $\operatorname{sen} \theta=0,8$ e $\cos \theta=0,6$. Adotando $\mathrm{g}=10 \mathrm{~m} / \mathrm{s}^{2}$, determine:

a) os módulos das componentes horizontal e vertical da velocidade no instante de lançamento;

o instante em que o corpo atinge o ponto mais alto da trajetória;

a altura máxima atingida pelo corpo;

o alcance do lançamento;

\subsection{AVALIAÇÃO ESTUDANTIL SOBRE A FÍSICA TRADICIONAL E A FÍSICA COM O USO DO MODELLUS}

Aprofundando em um âmbito educacional, é possível divergir os métodos de ensino tradicionais expositivos de métodos significativos. Necessita-se primeiro entender a abordagem tradicional:

"Como se sabe, o adulto, na concepção tradicional, é considerado como homem acabado, "pronto" e o aluno um "adulto em miniatura", que precisa ser atualizado. O ensino, em todas as suas formas, nessa abordagem, será centrado no professor. Este tipo de ensino volta-se para o que é externo ao aluno: o programa, as disciplinas, o professor. $O$ aluno apenas executa prescrições que lhe são fixadas por autoridades exteriores" (MIZUKAMI, 1986, p. 8)

Esse processo é bastante visto em salas de aula, como exemplo, uma aula expositiva de Física com um professor realizando exercícios ao quadro pode implicar nos 
resultados obtidos sobre o desempenho dos estudantes. Conforme Pelizzari, Kriegl, Baron, Finck e Dorocinski (2002, p 38), com base no estudo de Ausubel, temos uma outra perspectiva, a partir da abordagem significativa:

"A aprendizagem é muito mais significativa à medida que o novo conteúdo é incorporado às estruturas de conhecimento de um aluno e adquire significado para ele a partir da relação com seu conhecimento prévio. Ao contrário, ela se torna mecânica ou repetitiva, uma vez que se produziu menos essa incorporação e atribuição de significado, e o novo conteúdo passa a ser armazenado isoladamente ou por meio de associações arbitrárias na estrutura cognitiva."

Fazendo uso das ideias de Santos, Alves e Moret e Santos (2006), utilizamos um questionário com a finalidade de avaliar os conhecimentos dos estudantes que participaram. Os envolvidos constituem os Curso Técnico do Ensino Médio, com um total de 15 alunos. Seguiu-se a primeira etapa com questões sem o conhecimento dos estudantes sobre o Modellus, como uma forma de avaliar os métodos de educação em sala de aula.

1. Qual a sua relação com a disciplina de Física? (Não gosto; Gosto um pouco; Gosto; Gosto Muito)

2. Você sentiu dificuldade no estudo de Lançamento Vertical e Lançamento Oblíquo? (Sim; Pouca; Não)

3. Exercício proposto de Lançamento Vertical

4. Exercício proposto de Lançamento Oblíquo

5. Você acredita que os métodos tradicionais de ensino podem influenciar na falta de interesse da disciplina? (Não; Um pouco; Tanto Faz; Sim; Bastante)

6. Você acredita que o uso de softwares podem contribuir para o entendimento tanto da disciplina de Matemática quanto de Física? (Não; Um pouco; Tanto Faz; Sim; Bastante)

Em seguida, foi realizada uma apresentação expositiva acerca do Modellus, destacando suas aplicações e contribuições para o ensino da Física e da Matemática. 
Após essa introdução, os exercícios utilizados no questionário anterior foram aplicados no software, analisando as informações dispostas na simulação dos mesmos. Finalizou-se com uma segunda etapa constituída de um questionário acerca do uso do Modellus uma vez apresentado:

1. O uso da modelagem computacional facilitou no entendimento dos exercícios propostos? (Não; Um pouco; Tanto Faz; Sim; Bastante)

Você sentiu dificuldade na forma que o programa apresenta seus resultados? (Não; Um pouco; Tanto faz; Sim; Bastante)

Você acredita que o uso de softwares como o Modellus poderiam ser utilizados em sala de aula para contribuir assim no ensino da Física? (Não; Tanto faz; Sim)

Qual a sua consideração final acerca do trabalho realizado? (Questão discursiva)

\section{RESULTADOS E DISCUSSÕES}

\subsection{EXERCÍCIOS APLICADOS NO MODELLUS}

No exercício 1 de Lançamento Vertical, são requisitados o instante e a posição de encontro dos móveis $\mathrm{A}$ e $\mathrm{B}$. Considerando que $\mathrm{sA}=\mathrm{sB}$, torna-se fácil utilizar a função horária de espaço para encontrar o instante de encontro $(\mathrm{t}=2,5 \mathrm{~s})$ e mais tarde encontrar a posição ( $\mathrm{sA}=\mathrm{sB}=6,25 \mathrm{~m}$ ).

Já no exercício 2 de Lançamento Oblíquo, busca-se módulo da velocidade no instante inicial do lançamento, tanto horizontalmente $(\mathrm{Vx}=60 \mathrm{~m} / \mathrm{s})$ quanto verticalmente $(\mathrm{V} 0 \mathrm{y}=80 \mathrm{~m} / \mathrm{s})$, assim como o instante do corpo no ponto mais alto ( $\mathrm{t}=8 \mathrm{~s})$, a altura máxima da trajetória $(\mathrm{H}=320 \mathrm{~m})$ e o alcance do lançamento $(A=960 \mathrm{~m})$. Utilizando as operações matemáticas de movimento horizontal, é possível encontrar os respectivos resultados.

Ambos os exercícios são facilmente encontrados em livros didáticos ou na própria Internet com suas mais variadas resoluções. O que pode parecer um simples 
problema para um determinado aluno, pode causar certo desconforto para outros, sendo isso um ponto para problematização sobre como os métodos tradicionais podem estar influenciando em tais resultados.

O uso da modelagem computacional vem como uma perspectiva para alterar esse cenário. Tendo o desenvolvimento dos problemas anteriores no software Modellus, é possível obter uma amplitude nos resultados, como mostra figura 4 :

Figura 4 - Modelo Matemático para o exercício proposto de Lançamento Vertical no Modellus (Autores, 2017)

\begin{tabular}{|l|}
\hline Modelo Matemático \\
\hline$x=v x \times t$ \\
$y=V y O \times t-\frac{g}{2} \times t^{2}$ \\
$g=10$ \\
$V O=100$ \\
$V y O=v O \times 0.8$ \\
$V x=v O \times 0.6$ \\
$v y=V y O-g \times t$ \\
\hline Parâmetros Condiçoes Inicaís \\
\hline
\end{tabular}


Figura 5 - Simulação do exercício proposto de Lançamento Vertical no Modellus (Autores, 2017)

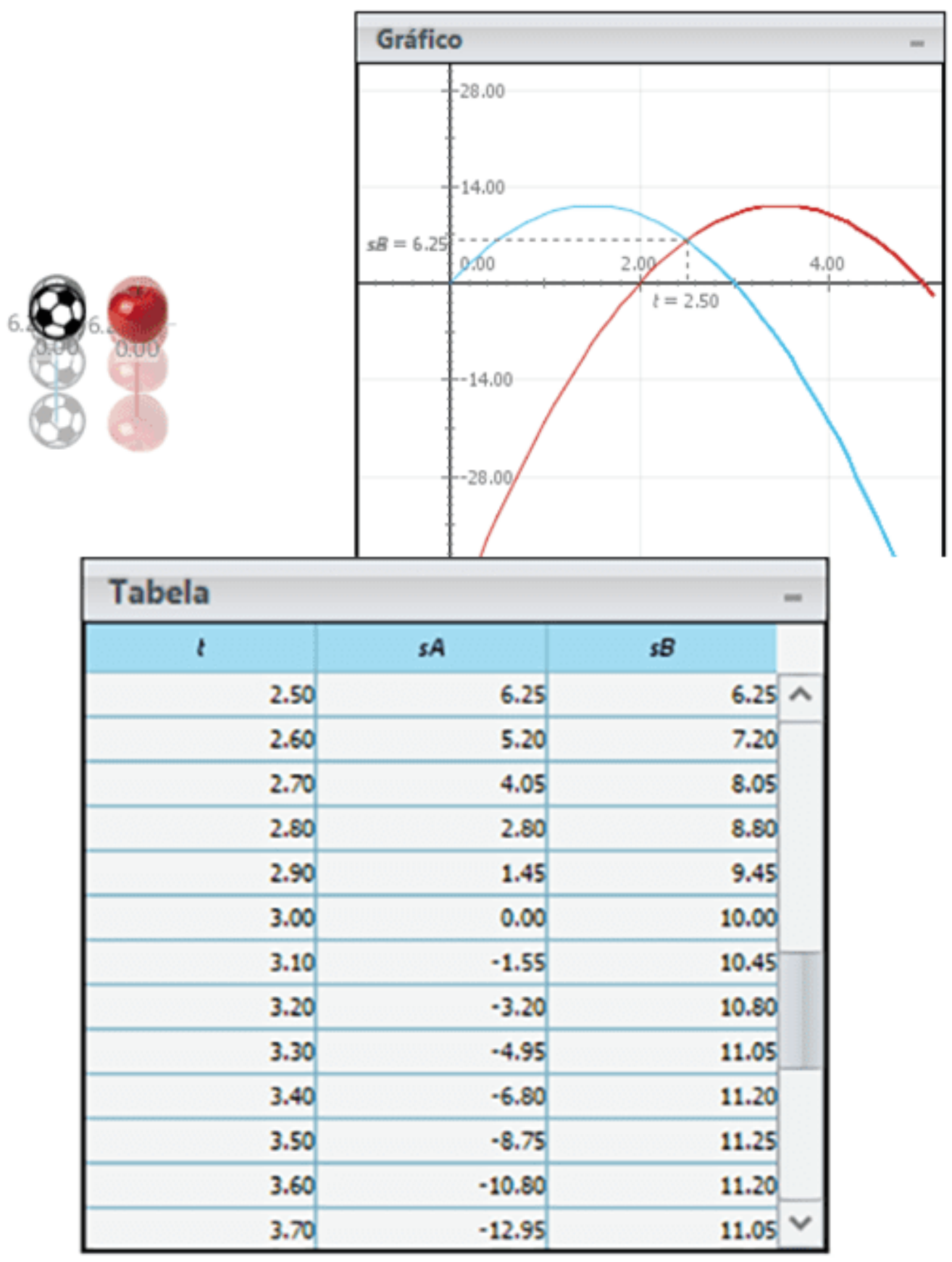

O software dependerá da descrição das funções matemáticas para serem aplicadas, possibilitando obter o resultado por meio de animações, gráficos e tabelas. Os dois corpos obedecem às funções. Na figura 5 , está presente o instante de encontro dos corpos, visto através de seus respectivos gráfico e tabela. Pela tabela, o instante 
$(\mathrm{t}=2,5 \mathrm{~s})$ mostra o momento de encontro em que $\mathrm{Sa}=\mathrm{Sb}$, assim como o gráfico das posições em função do tempo, estando de acordo o ponto de encontro.

Para a situação problema seguinte, conforme a figura 6 , houve igualmente uma aplicação por meio da modelagem computacional

Figura 6 - Modelo matemático ao exercício proposto de Lançamento Oblíquo no Modellus (Autores, 2017)

\begin{tabular}{|l||}
\hline Modelo Matemático \\
\hline$S A=s O+v O \times t-a \times t^{2}$ \\
$S O=0$ \\
$V O=15$ \\
$a=5$ \\
$S B=s O+v O \times(t-2)-a \times(t-2)^{2}$ \\
$S A=s B$ \\
\hline Parámetros Condigóes inicials \\
\hline
\end{tabular}


Figura 7 - Simulação do exercício proposto de Lançamento Oblíquo no Modellus (Autores, 2017)

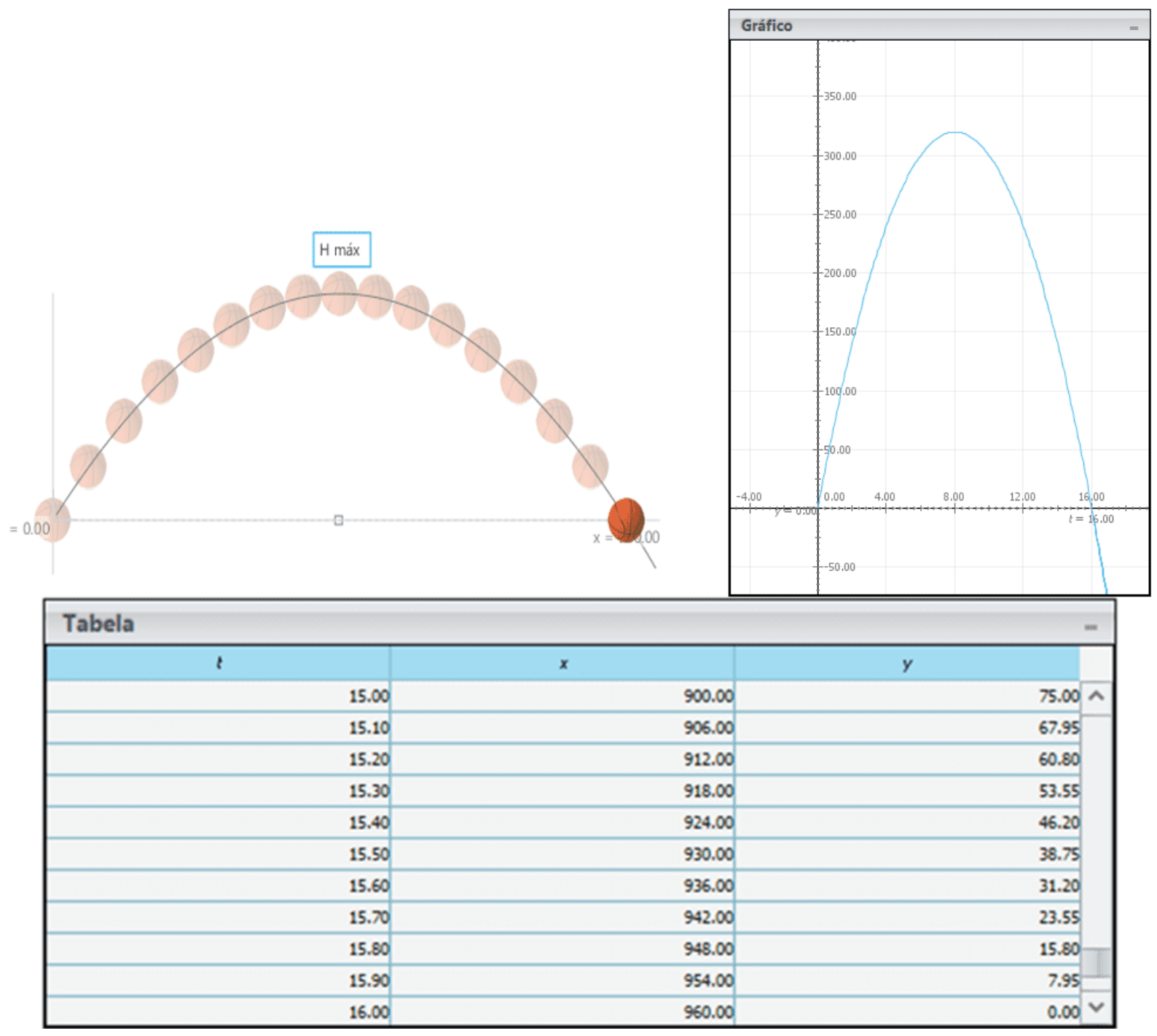

A partir da simulação, conforme a figura 7, é possível analisar os resultados questionados, como a exemplo do alcance do lançamento $A=960 \mathrm{~m}$, ou o instante $t$ no ponto mais alto como $8 \mathrm{~s}$. Certos valores podem ser facilmente obtidos, por exemplo, por meio gráfico no programa, como a respeito da altura máxima $\mathrm{H}=320 \mathrm{~m}$, vista pelo eixo $\mathrm{Y}$. 
Vale ressaltar que o programa possibilita dinamizar suas simulações, a exemplo de alterar a partícula para uma bola de futebol ou de basquete, adicionar imagens ao fundo da animação e alterar as cores no gráfico e os dados que elas irão dispor, possibilitando assim uma maior interação do usuário com o seu ambiente de trabalho.

\subsection{RESULTADOS OBTIDOS NA AVALIAÇÃO ESTUDANTIL}

Através do questionário avaliativo, obtiveram-se as perspectivas anteriores à introdução do Modellus e posteriores. Deu-se início com as questões anteriores da primeira etapa, mas como uma forma avaliativa do ensino atual da Física na perspectiva do estudante:

Figura 8 - Gráfico da Questão 1 da primeira etapa (Autores, 2017)

1. Qual sua relação com a disciplina de Física?

\section{Respostas}

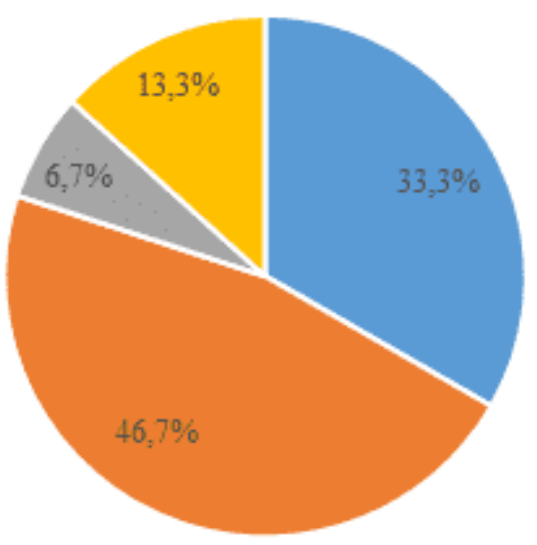

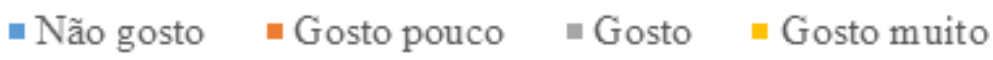


Figura 9 - Gráfico da Questão 2 da primeira etapa (Autores, 2017)

2. Você sentiu dificuldade no estudo de Lançamento Vertical e Lançamento Oblíquo?

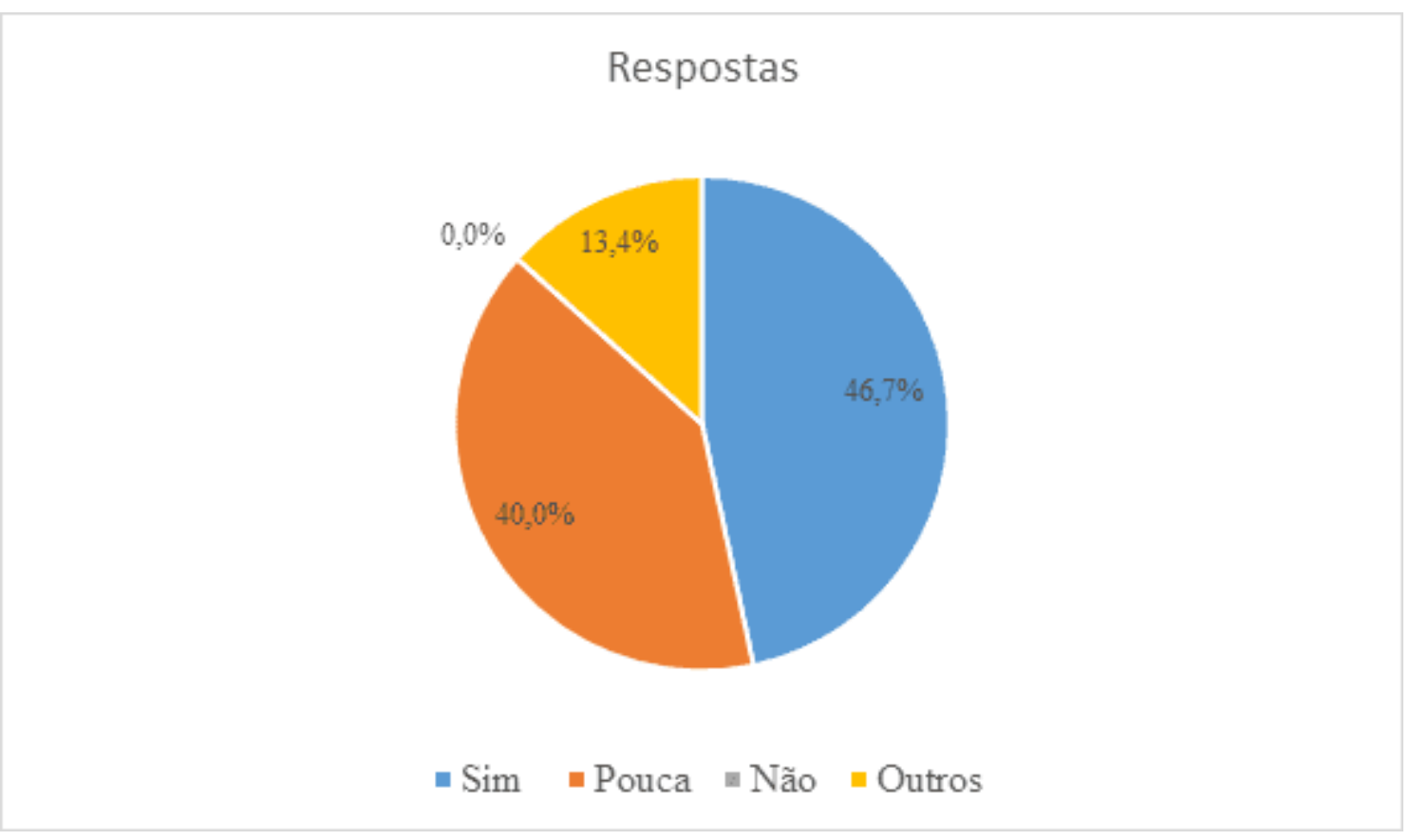


Figura 10 - Gráfico da Questão 3 da primeira etapa (Autores, 2017)

3. Ex. 01. (Lançamento Vertical) Dois móveis $A$ e $B$ são lançados verticalmente para cima, com a mesma velocidade inicial de $15 \mathrm{~m} / \mathrm{s}^{2}$, do mesmo ponto. O móvel A é lançado no instante $\mathrm{t}=0 \mathrm{~s}$ e o móvel $\mathrm{B}$ é lançado $2 \mathrm{~s}$ depois. Determine, a contar do ponto de lançamento, a posição e o instante do encontro dos móveis. Adote $\mathrm{g}=10 \mathrm{~m} / \mathrm{s}^{2}$ e despreze a resistência do ar.

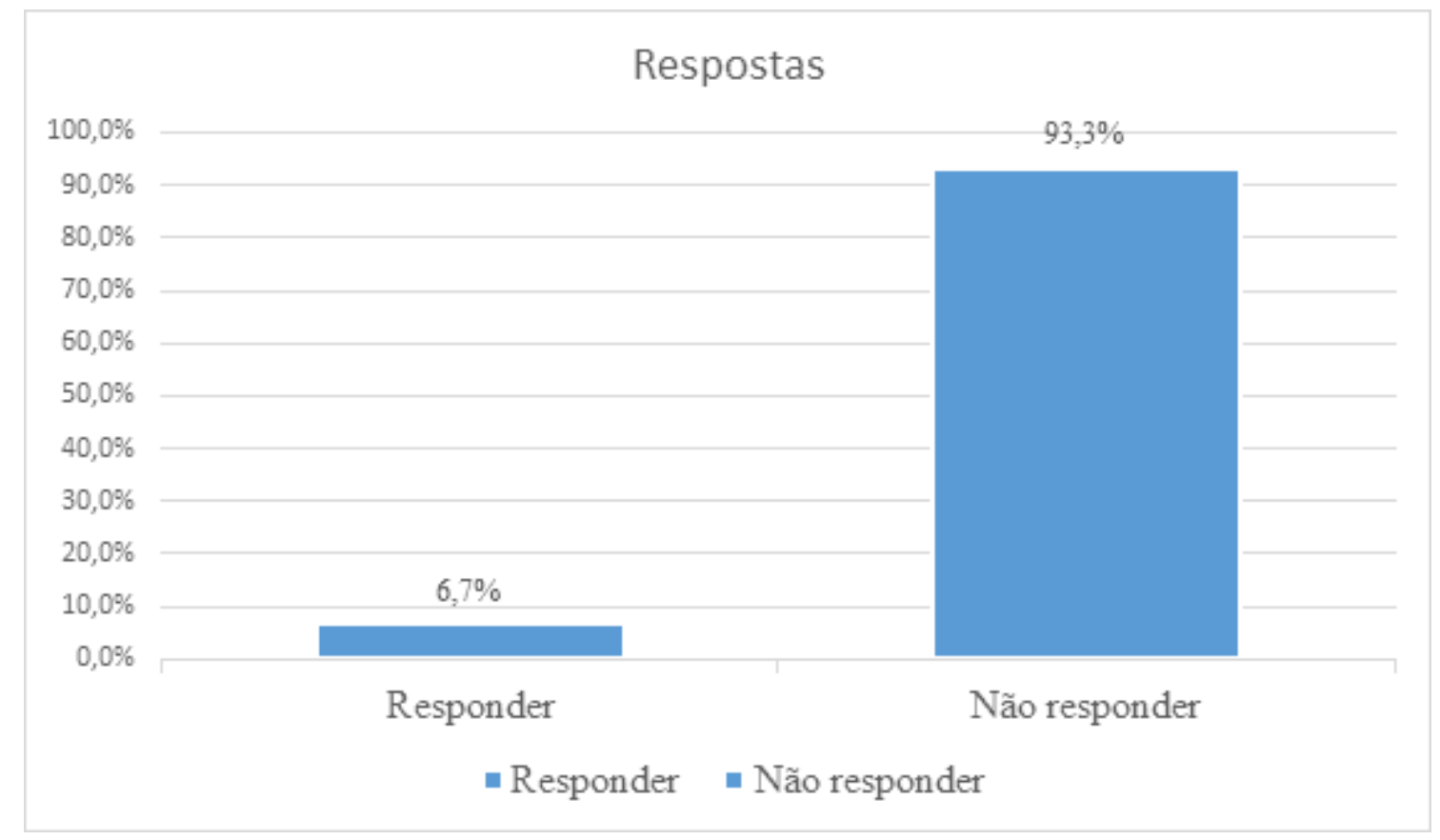


Figura 11 - Gráfico da Questão 4 da primeira etapa (Autores, 2017)

4. Ex. 02. (Lançamento Oblíquo) Um corpo é lançado obliquamente no vácuo com velocidade inicial $\mathrm{v} 0=100 \mathrm{~m} / \mathrm{s}$, numa direção que forma com a horizontal um ângulo $\theta$ tal que $\operatorname{sen} \theta=0,8$ e $\cos \theta=0,6$. Adotando $\mathrm{g}=10 \mathrm{~m} / \mathrm{s}^{2}$, determine: a) os módulos das componentes horizontal e vertical da velocidade no instante de lançamento; b) o instante em que o corpo atinge o ponto mais alto da trajetória; c) a altura máxima atingida pelo corpo; d) o alcance do lançamento.

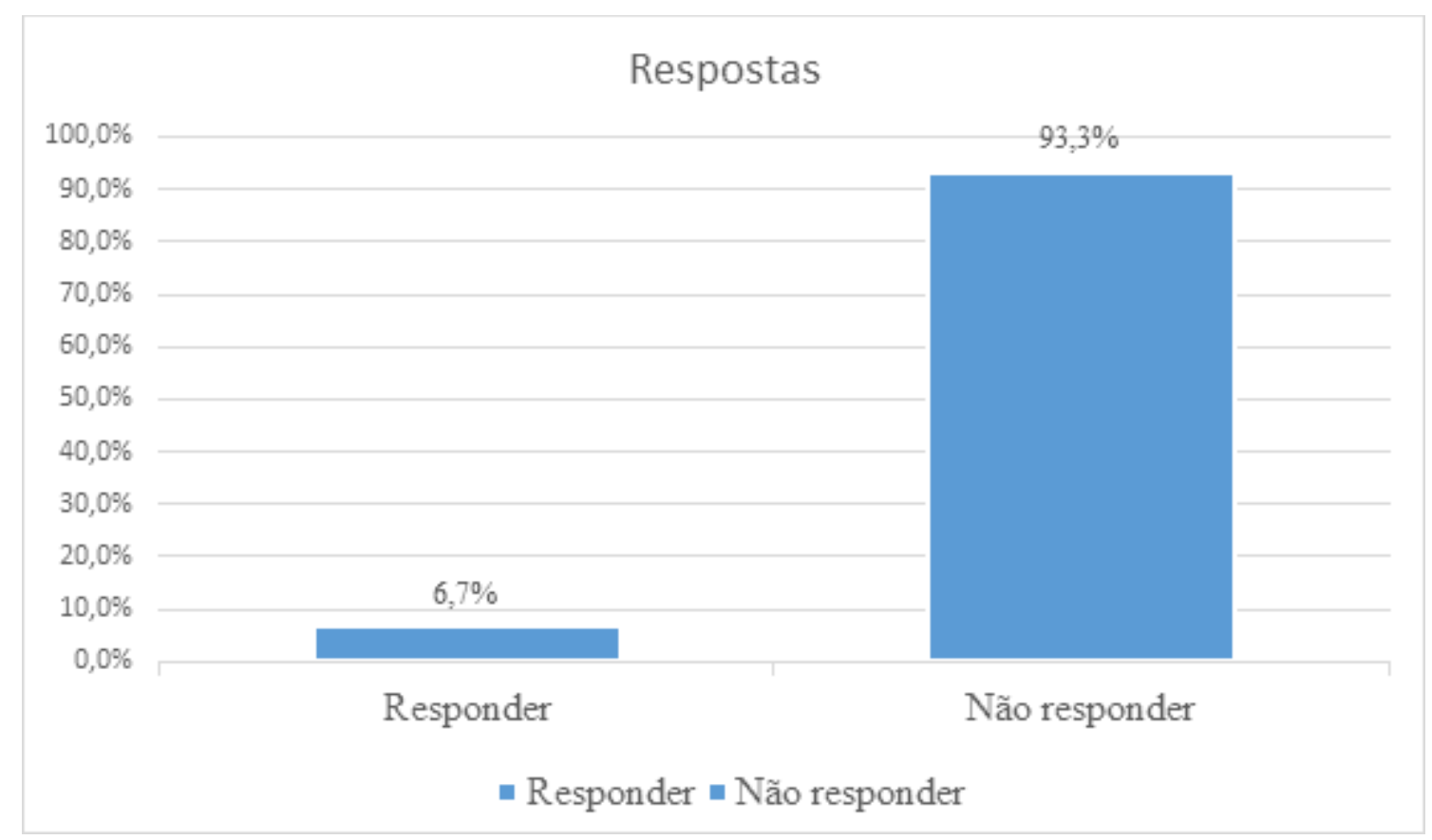


Figura 12 - Gráfico da Questão 5 da primeira etapa (Autores, 2017)

5. Você acredita que os métodos tradicionais de ensino podem influenciar na falta de interesse pela disciplina?

\section{Respostas}

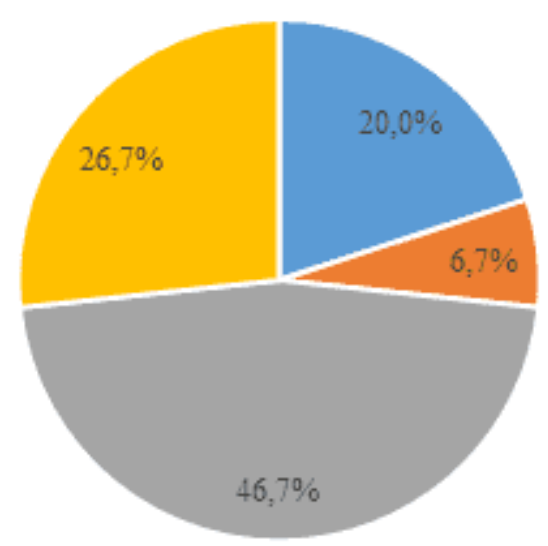

" Não " Talvez "Sim "Bastante 
Figura 13 - Gráfico da Questão 6 da primeira etapa (Autores, 2017)

6. Você acredita que o uso de outros métodos de ensino (softwares, aulas práticas, etc.) podem contribuir para o entendimento tanto da disciplina de Matemática quanto de Física?

\section{Respostas}

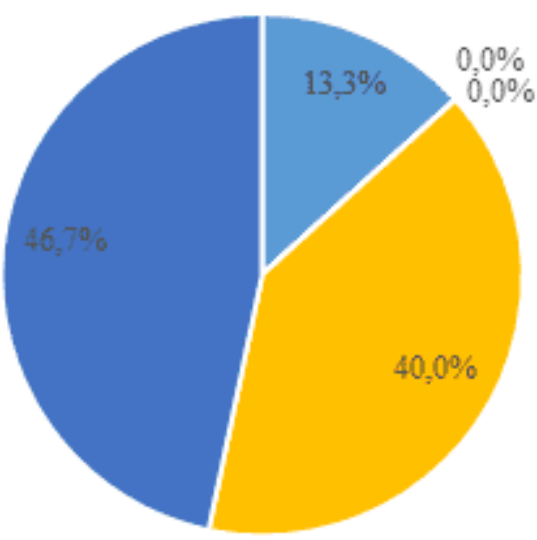

- Não - Um pouco $\quad$ - Tanto faz $\quad$ - Sim - Bastante

De maneira geral, podemos analisar em primeiro instante, conforme o gráfico da figura 8, que boa parte dos participantes não possuem um amplo interesse acerca da Física: uma majoritária parcela apresentou que gostava um pouco da Física enquanto disciplina ou que não gostava, fator também presente na segunda questão, conforme o gráfico da figura 10, em que uma maioria sentiu dificuldade no aprendizado dos temas trabalhados ou sentiu pouca dificuldade. Há o exemplo de um participante que havia estudo os conteúdos sozinho.

Em relação aos dois exercícios trabalhados, nota-se que apenas um participante se propôs a resolver as questões, enquanto os demais deixaram-nas em branco, conforme as figuras 10 e 11 . É possível relacionar tal fator com a própria falta de interesse nos dois temas dispostos, na atividade avaliativa em si ou pela própria dificuldade no assunto. Para Veit e Teodoro (2002), "na prática, Física representa para o estudante, na maior parte das vezes, uma disciplina muito difícil, em que é preciso 
decorar fórmulas cuja origem e finalidade são desconhecidas". Independente do motivo em questão, é importante atentar-se para que os estudantes apresentem maior interesse ou possam minimizar suas dificuldades de maneira ampla.

As duas últimas questões apresentam como uma perspectiva geral que virá de uma visão do participante em si, mas numa visão ampla sobre os métodos que compõem o ensino da ciência atualmente. A maioria dos participantes apontou, conforme a figura 12, que a forma tradicional de ensino pode influenciar no interesse pela disciplina, além de que outras metodologias poderiam ser mais utilizadas, conforme a figura 13. Podemos aliar conforme Lima e Vasconcelos (2006, p. 399) com base no estudo de Krasilchik (2004, p. 184):

"O docente, por falta de autoconfiança, de preparo, ou por comodismo, restringe-se a apresentar aos alunos, com o mínimo de modificações, o material previamente elaborado por autores que são aceitos como autoridades. Apoiado em material planejado por outros e produzido industrialmente, o professor abre mão de sua autonomia e liberdade, tornando-se simplesmente um técnico."

Partimos assim de uma visão em que os estudantes não se sentem amplamente satisfeitos com a forma que aprendem ou aprenderam - sendo assim acreditado - a disciplina. Uma aula expositiva monótona com uma massiva quantidade de cálculos seria um exemplo.

Segue assim com a segunda parte da avaliação via questionário, constituindo mais uma opinião acerca do Modellus e suas aplicações. Após a apresentação do mesmo, os participantes foram requisitados a avaliá-lo, tornando possível analisar se os participantes se sentiram motivados ou não à tecnologia: 
Figura 14 - Questão 1 da segunda etapa (Autores, 2017)

1. O uso da modelagem computacional facilitou no entendimento dos exercícios propostos?

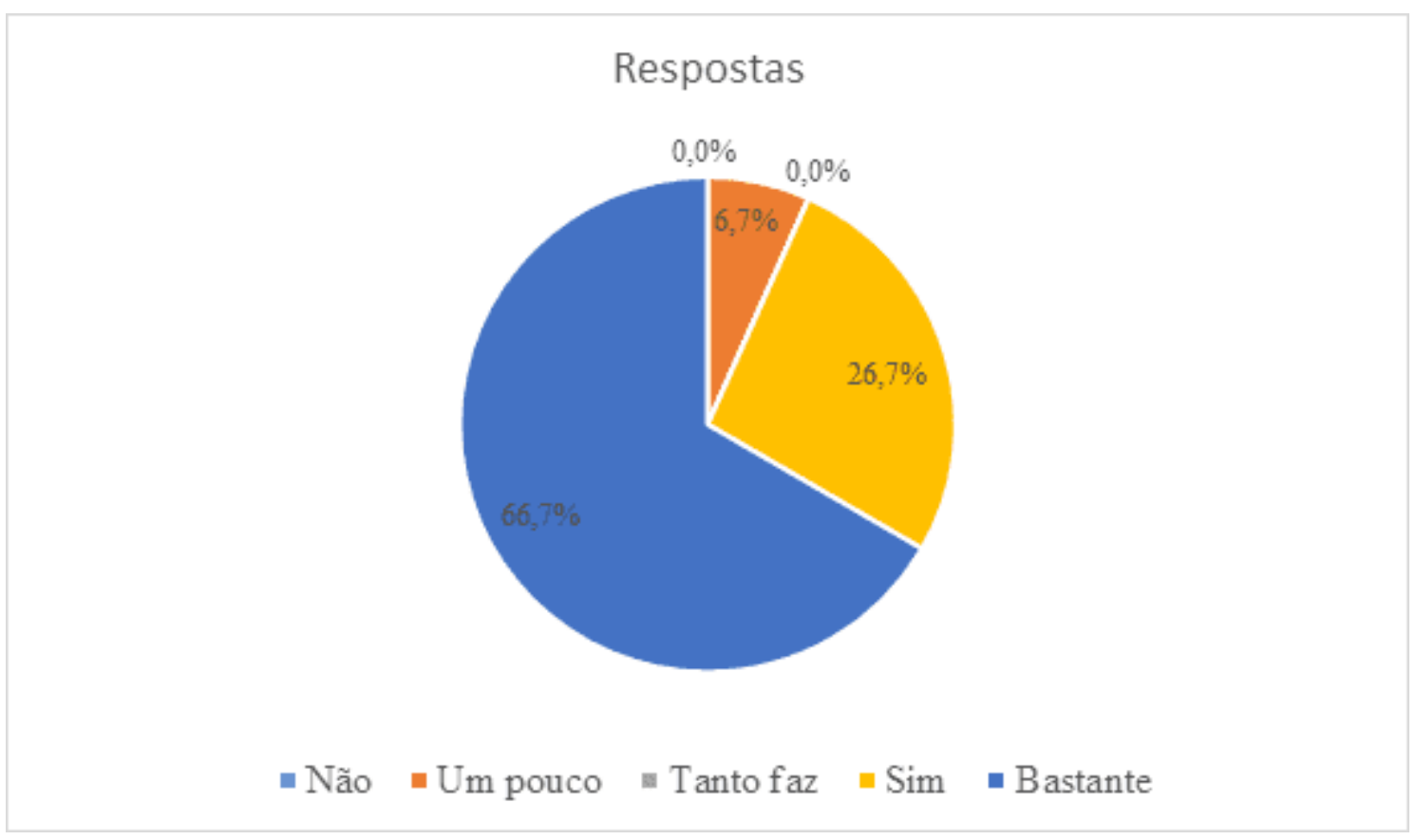


Figura 15 - Questão 2 da segunda etapa (Autores, 2017)

2. Você sentiu dificuldade na forma que o programa apresenta seus resultados?

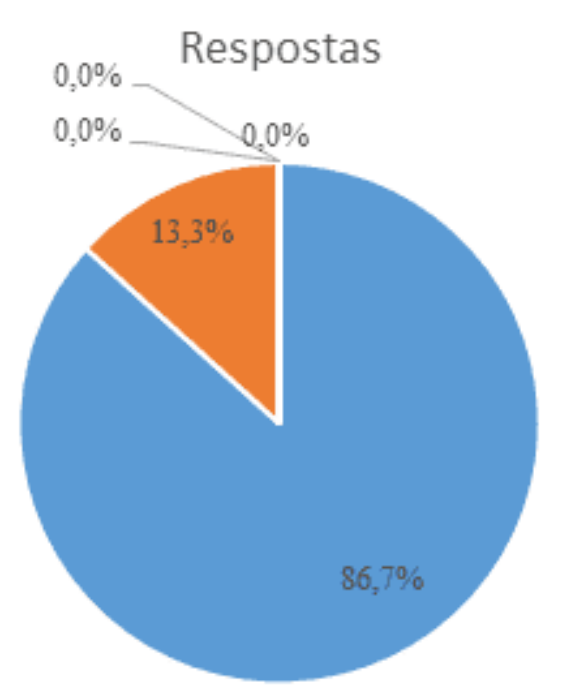

- Não " Um pouco = Tanto faz $\|$ Sim - Bastante 
Figura 16 - Questão 3 da segunda etapa (Autores, 2017)

3. Você acredita que o uso de softwares como o Modellus poderiam ser utilizados em sala de aula para contribuir assim no ensino da Física?

\section{Respostas}

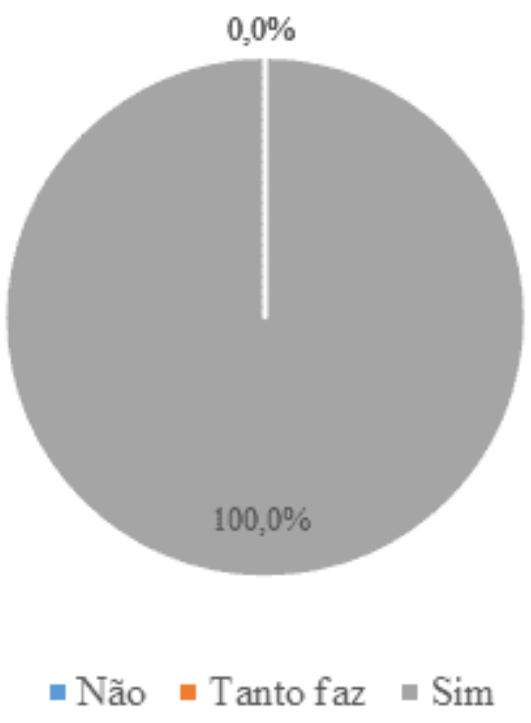

Nota-se que as respostas foram bastante positivas quanto ao Modellus como método de ensino, tendo uma maioria afirmando que o uso da modelagem computacional facilitou o entendimento dos exercícios, mesmo que um pouco. Em seguida, apenas uma pequena parcela apresentou uma certa dificuldade acerca do uso do Modellus, enquanto a maioria não apresentou tal feito.

Todos mostraram confiança no uso do software como forma de ensino da Física, com uma aprovação de $100 \%$ do mesmo. Finalizou assim com as considerações finais dos participantes, onde foram apresentadas perspectivas voltadas para a aplicação do Modellus e sugestões de melhorias como forma de aprimorar ainda mais o uso do programa:

4. Qual a sua consideração final acerca do trabalho realizado?

- É uma boa proposta a implementação deste software nas aulas de física! 
- O aplicativo apresentado apresenta ser de grande utilidade, já que tem como fim, facilitar o processo de aprendizagem em assuntos voltados para a matéria de física, tornando o assunto mais interativo e dinâmico.

- Um trabalho muito bom, eu sou horrível em física e sinceramente eu aprendi um assunto que achei ser impossível

- O projeto apresenta uma maneira diferente de enxergar a física

- Um ótimo recurso..

- Muito boa e rica para o aprendizado

- Achei muito bom o trabalho, pois facilitou muito o entendimento dos exercícios propostos visto que a forma ilustrativa de ensino facilita para os estudantes.

- Acredito que o software Modellus deve ser implementado nas aulas de física

- O aplicativo é muito interessante, e com certeza ajudará no ensino e aprendizagem da disciplina de Física, sendo inclusive lúdico.

- O trabalho do grupo foi, no mínimo, interessante. Considerando a intenção mencionada, o esforço aplicado e principalmente a intenção juntamente com suas ações. O projeto merece sim, em minha opinião, uma atenção especial e tentativas para sua aplicação em sala de aula, pois, a Física (como ciência e disciplina) se tornará algo mais complexo do que é sem uma metodologia adequada. Consequentemente, aumentará ainda mais o "pavor" dos alunos quanto a ela. Dessa forma e, portanto, o trabalho da dupla deve ser considerado como uma ótima "tentativa metodológica".

- Foi um trabalho bem realizado e de fácil entendimento

- Em relação ao programa, acho que tem que ter mais organização na separação dos dados e os ícones de animação. Achei muito interessante, e poderia utilizá-lo durante 
as aulas. Principalmente quando precisarmos de resultados rápidos. Um elogio ao programa é quando usaram as imagens na representação dos resultados.

- Muito criativo e ajuda bastante na interpretação da questão, acho um bom instrumento para utilização em sala de aula e trabalhos.

- O trabalho realizado é bastante interessante, e seria de grande valia o uso deste na sala de aula, para que nós, alunos possamos observar de forma mais explícita.

- É uma contribuição para o ensino de física aumentando ainda mais o entendimento sobre os variados assuntos, ainda que exija a melhoria em relação ao uso adequado desse software, acredito que deve ser de muita utilidade.

\section{CONSIDERAÇÕES FINAIS}

Pesquisas educacionais na área do ensino em Física mostram que há um déficit no aprendizado, seja por dificuldade da disciplina, metodologia dos professores, materiais utilizados, entre outros. O uso de tecnologias seria uma forma de compensar esta "falha" no sistema, já que o campo técnico informacional se tornou muito grande atualmente, sendo usado em várias áreas do conhecimento humano. Deste ponto de vista, como solução, é trazido o software Modellus como material de apoio ao ensino de conceitos físicos, manipulando variáveis, animações, tabelas e gráficos.

O programa foi escolhido justamente por ser gratuito, e permitir a visualização da animação e dos valores de variáveis e parâmetros usados no mesmo. Ele se encaixa muito bem no âmbito educacional, sendo utilizado com o objetivo central de interpretação do que as grandezas físicas influenciam em um sistema, além do desenvolvimento do conhecimento estrutural dos modelos através de equações que representam o movimento de um objeto, direção deste, etc.

Como o software trabalha com movimentos, foi inevitável fugir de assuntos recorrentes à cinemática, portanto, apresentou-se exercícios de Lançamento Vertical e Lançamento Oblíquo como forma de teste do programa. Obtém-se dos estudos de Veit e Teodoro (2002), Solano (2002), outras referências e do próprio teste, que 
através de uma interface simples, o Modellus desenvolve o pensamento dos usuários e ajuda no ensino de Física com animações interativas, podendo até ser comparado ao "Word Office" a sua área de trabalho.

Com o questionário realizado acerca do Modellus utilizando os exercícios do assuntos Lançamento Vertical e Lançamento Oblíquo, obteve-se na primeira avaliação que pouco mais de $75 \%$ dos avaliados, não gostam ou gostam pouco de Física, tendo uma relação ruim com a mesma. É um dado importante à pesquisa, já que na segunda parte, após mostrar os assuntos usando o programa, 100\% dos avaliados responderam que o software é benéfico na aprendizagem, mostrando como o uso de outras metodologias, principalmente, utilizando tecnologias pode ser um recurso excelente ao ensino de Física.

Modellus ainda não é muito conhecido no Brasil, talvez por uma questão do sistema educacional, que é considerado antigo e com base em séculos passados por muitos autores, que não regulamenta muita formas de ensino diversificadas para o investimento das áreas. Isso pode ser o problema do não uso do programa, que como constatado, auxilia muito na aprendizagem de ciências exatas, sendo abordado neste presente artigo a área de Física. A solução para elevar os números em Educação do país em rankings mundiais pode ser diversificar as metodologias usadas no ensino, $\mathrm{e}$ o uso do Modellus seria uma prática importantíssima a esta necessidade.

\section{REFERÊNCIAS}

ALIPRANDINI, Daiane Maria; SCHUHMACHER, Elcio; SANTOS, Muriel Clasen dos. Processo Ensino e Aprendizagem de Física apoiada em software de modelagem. In: I SIMPÓSIO NACIONAL DE ENSINO DE CIÊNCIA E TECNOLOGIA, 1., 2009, Ponta Grossa. Ciência e Tecnologia. Blumenau: Francisco; Junior; Pinheiro, 2009. p. $1370-1380$.

ARAUJO, Ives Solano. Um Estudo sobre o Desempenho de Alunos de Física Usuários Da Ferramenta Computacional Modellus na Interpretação de Gráficos 
em Cinemática. 2002. 109 f. Dissertação (Mestrado) - Curso de Física, Instituto de Física, Universidade Federal do Rio Grande do Sul, Porto Alegre, 2002.

KRASILCHIK, M. Prática de ensino de biologia. 4. ed. São Paulo: Ed. da USP, p.198, 2004.

LIMA, Kênio Erithon Cavalcante; VASCONCELOS, Simão Dias. Análise da metodologia de ensino de ciências nas escolas da rede municipal de Recife. Ensaio: aval.pol.públ.Educ., Rio de Janeiro , v. 14, n. 52, p. 399,Set. 2006 . Disponível em:<http://www.scielo.br/scielo.php?script=sci_arttext\&pid=S0104$40362006000300008 \& \operatorname{lng}=e n \& n r m=i s o$ >. Acesso em: 05 out. 2017.

LOPES, Rosemara; FEITOSA, Eloi. Applets Como Recurso Pedagógico No Ensino De Física: Aplicação Em Cinemática. In: SIMPÓSIO NACIONAL DE ENSINO DE FíSICA - SNEEF, 18., 2009, Vitória. Simpósio. Vitória: Unesp, 2009. p. 1 - 9.

MIZUKAMI, Maria da Graça Nicoletti. Abordagem Tradicional. In: MIZUKAMI, Maria da Graça Nicoletti. Ensino: As abordagens do Processo. São Paulo: Epu, 1986. Cap. 1. p. 7-18. Disponível em: <https://www.docdroid.net/MrZCc0F/maria-das-gracasnicoletti-mizukami-ensino-as-abordagens-do-processo.pdf\#page=14>. Acesso em: 05 out. 2017.

PELIZZARI, Adriana; KRIEGL, Maria de Lurdes; BARON, Márcia Pirih; FINCK, Nelcy Teresinha Lubi; DOROCINSKI, Solange Inês. Teoria da Aprendizagem Significativa Segundo Ausubel. Pec, Curitiba, v. 2, n. 1, p.37-42, jul. 2002.

RAMALHO JUNIOR, Francisco; FERRARO, Nicolau Gilberto; SOARES, Paulo Antônio de Toledo. Lançamento horizontal e lançamento oblíquo no vácuo. In: RAMALHO JUNIOR, Francisco; FERRARO, Nicolau Gilberto; SOARES, Paulo Antônio de Toledo. Os Fundamentos da Física 1: Mecânica. 9. ed. São Paulo: Moderna, 2007. Cap. 9. p. 144-162.

ROSA, Cleci Werner da; PEREZ, Carlos Ariel Samudio; DRUM, Carla. Ensino de Física nas Séries Iniciais: Concepções da Prática Docente. Revista 
Investigações em Ensino de Ciências (ienci), Porto Alegre, v. 12, n. 3, p.357-368, 09 out. 2009.

SANTOS, Gustavo H.; ALVES, Lynn; MORET, Marcelo A.. Modellus: Animações Interativas Mediando a Aprendizagem Significativa dos Conceitos de Física no Ensino Médio. Sitientibus: Série Ciências Físicas, Feira de Santana, v. 2, n. 7, p.56-67, nov. 2006. Anual. Disponível em: <http://dfis.uefs.br/sitientibus/vol2/Expediente2006_Main-SPSS.pdf>. Acesso em: 18 ago. 2017.

TEIXEIRA, Ricardo Roberto Plaza; JÚNIOR, Modesto Pantaleo; GOLFETTE, Bruno Henrique. PERFIL DOS PROFESSORES DE FÍSICA DO ENSINO MÉDIO EM SÃO PAULO. 2004. Disponível em: <http://www.ufpa.br/ensinofts/perfilpfsp.html>. Acesso em: 20 dez. 2005.

VEIT, E. A.; TEODORO, V. D.. Modelagem no Ensino: Aprendizagem de Física e os Novos Parâmetros Curriculares Nacionais para o Ensino Médio. Revista Brasileira de Ensino de Física, São Paulo, v. 24, n. 2, p.87-95, jul. 2002. Disponível

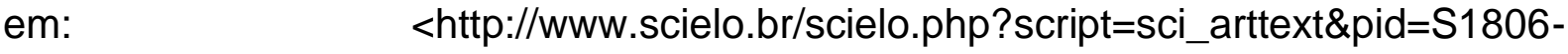
$11172002000200003 \&$ Ing=en\&nrm=iso >. Acesso em: 17 set. 2017.

Enviado: Setembro, 2019.

Aprovado: Março, 2020. 